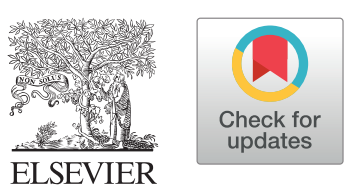

CJC Open 3 (2021) S4-S8

\title{
Editorial
}

\section{Bringing Intersectionality to Cardiovascular Health Research in Canada}

\author{
Saleema Allana, MScN, RN, ${ }^{\mathrm{a}, \mathrm{b}}$ Chantal F. Ski, PhD, ${ }^{\mathrm{c}}$ David R. Thompson, PhD, ${ }^{\mathrm{d}}$ and \\ Alexander M. Clark, $\mathrm{PhD}^{\mathrm{e}}$ \\ ${ }^{a}$ Faculty of Nursing, University of Alberta, Edmonton, Alberta, Canada \\ ${ }^{b}$ Arthur Labatt Family School of Nursing, University of Western Ontario, London, Ontario, Canada \\ 'Integrated Care Academy, University of Suffolk, Ipswich, United Kingdom \\ ${ }^{d}$ School of Nursing and Midwifery, Queen's University Belfast, Belfast, United Kingdom \\ ${ }^{e}$ Faculty of Health Disciplines, Athabasca University. Edmonton, Alberta, Canada
}

Cardiovascular disease (CVD) affects various subgroups of the population; some are disproportionately affected more than others. ${ }^{1,2}$ Besides genetic and clinical factors, an important set of social factors intersect to shape our cardiovascular health outcomes. Disparities in CVD are numerous and wideranging, having evolved mainly from inequalities in society. Some populations carry a higher risk of CVDs, a higher prevalence of CVDs, and worse outcomes with CVDs.

Race, immigration status, sex, gender, and sexual orientation are some examples of the social factors that can determine not only our risk of heart disease but also our responses to therapies and our access to services. ${ }^{3-6}$ These factors compound existing health inequities, but they are less isolated factors than they are intersecting factors. Consequently, an understanding of how this intersectionality influences cardiovascular health outcomes is now key.

Therefore, this paper calls for bringing an intersectionality lens to cardiovascular health research, which eventually would enable us to practice intersectionality-based cardiovascular medicine.

\section{What Is Intersectionality?}

Intersectionality acknowledges the various identities that each of us carries, and how these identities intersect to bring about either oppression or privilege. ${ }^{7,8}$ As individuals, we are known socially by our identities, such as age, gender, sexual orientation, race/ethnicity, religion, social class, immigration status, and place of residence (rural/ urban). Each of these identities can put us in a position of relative power or

Received for publication June 16, 2021. Accepted August 28, 2021.

Ethics Statement: We have adhered to all relevant ethical guidelines. Corresponding author: Saleema Allana, Desk No. 5-284F, 5th Floor, Edmonton Clinic Health Academy (ECHA), 87 Ave and 114 St, Edmonton, Alberta T6G 1C9, Canada. Tel.: +1-780-935-2820.

E-mail: smallana@ualberta.ca

See page $\mathrm{S} 7$ for disclosure information. disadvantage; however, practically, each of these identities can also interact with other factors, thus reinforcing and compounding privilege, discrimination, and inequities. ${ }^{8}$ As examples of intersectionality, consider elderly rural women, an immigrant of South Asian descent, or a Black lesbian. These intersecting identities not only define us socially, but also have a lot to do with our health behaviours,and our physiological and psychosocial health, all of which contribute to our risk of acquiring and the outcomes of various diseases. CVD is no exception. About $90 \%$ of the risk of myocardial infarction comes from the 9 risk factors that are closely linked to our health behaviours, ${ }^{9}$ and a wide range of factors influence health services usage. ${ }^{10}$ For instance, older women with heart failure living in rural areas are less likely to follow self-care recommendations ${ }^{11}$; South-Asian immigrants have both an increased prevalence and an increased death rate from coronary artery disease ${ }^{12}$; and Black lesbian women tend to have a higher prevalence of cardiometabolic risk factors. ${ }^{13}$

Despite the fact that such intersecting factors can influence the incidence and treatment of CVD, intersectionality largely has been ignored in cardiovascular health research in Canada and globally, to date. Some studies have examined the intersection of race/ethnicity and sexual orientation and the contributions it makes toward developing the risk of CVD. ${ }^{13,14}$ Some studies have looked at the intersection of income and work status with the place of residence (rural/urban) and how it shapes self-care in heart failure. ${ }^{15,16}$ However, the vast majority of studies of cardiovascular health focus on singular factors and their impact on patient outcomes, leaving intersectionality and its effects unexplored and unacknowledged.

\section{Why Is Intersectionality Important for Exploration of the Cardiovascular Health of Canadians?}

The neglect of intersectionality in Canadian CVD research is notable because the Canadian population is immensely diverse - with unusually high cultural and gender diversity, 
along with significant rurality and indigeneity. ${ }^{17}$ Canada has accordingly come to be known as a land of immigrants and multiculturalism. Each year, Canada welcomes around 300,000 new immigrants of varied ethnic backgrounds. These individuals come from South Asia, South East Asia, the Middle East, the US, Africa, and Europe; they speak hundreds of different languages and bring with them their own unique cultures. ${ }^{18}$ In terms of gender diversity, about 900,000 Canadians described themselves as either lesbian, gay, or bisexual in the Canadian Community Health Survey (2015-2018), which is about $3.3 \%$ of the total Canadian population aged 15 years or more. ${ }^{19}$ Moreover, the Canadian population is a mix of people living in rural and urban areas, and of various social classes. Per 2019 statistics, about 19\% of Canadians live in rural remote areas, where access to healthcare is a major issue. ${ }^{20}$ Additionally, about $4 \%$ of Canadians identify themselves as Aboriginal or indigenous. ${ }^{21}$ This unusually high diversity within the Canadian population is also reflected among the Canadian cardiovascular patient populations. Therefore, it is extremely important to explore the effects of intersectionality on cardiovascular care and outcomes, especially in the Canadian context.

\section{Why Is Intersectionality Important for Cardiovascular Health Research?}

Cardiovascular health research is broad; it explores the prevalence and outcomes of CVDs, determines the efficacy of various treatment modalities, and examines self-care and disease management for chronic cardiac conditions, and the lived experiences of cardiovascular patients and caregivers. For each of these outcomes, several intersections of identities could be explored, which would result in generation of specific findings about the treatment/intervention or disease management program that is best suited to improve outcomes among specific populations of cardiovascular patients (see Table 1 for some examples of intersectionality-based cardiovascular research questions, outcome measures, and the intersections of identities explored).

Intersectionality applies everywhere. As much as it is imperative to account for intersectionality while predicting risks and outcomes of CVD and determining efficacy of treatments for specific patient groups, it is equally important to study health behaviours, self-care abilities, and lived experiences through an intersectionality lens.

Based on the type of outcome to be explored, the research methods can vary. Intersectionality embraces a broad range of research methods. For instance, epidemiologic studies could be conducted to determine risks, prevalence, and outcomes of CVD among various subgroups of the population that have intersecting factors affecting their cardiovascular health. Intersectionality-based interventional research can be carried out as a means to delineate the effectiveness of treatment modalities for various subgroups of cardiovascular patients. Mixed-methods research can be performed to explore self-care abilities and disease management among cardiac patients with intersecting identities. Lastly, intersectionality-based qualitative research could be undertaken to understand the experiences or perceptions of various subgroups of cardiac patients and their caregivers relating to living with and managing their condition. Important to note is that there is a stark need to move beyond what can be inferred from traditional cardiovascular research methods and more toward implementation of informative and inclusive interventions designed to address patient needs.

\section{In What Ways Can Intersectionality Be Applied to Cardiovascular Health Research?}

Intersectionality can be applied to cardiovascular health research in many different ways and at various levels. Intersectionality can be fully integrated through a research project, which means recognizing that the research is underpinned by the intersectionality theory, and subsequently weaving in intersectionality through each stage of the research. Alternatively, intersectionality could be applied at some or all of the stages of the research process (please see Fig. 1 for integration of intersectionality at various stages of the research process).

Even if the research is not entirely grounded in intersectionality theory, the influence of patients' intersecting identities on a specific cardiovascular health outcome can be

Table 1. Examples of intersectionality-based cardiovascular research questions with intersections of identities explored and outcome measures

\begin{tabular}{|c|c|c|c|}
\hline Subject \# & $\begin{array}{l}\text { Examples of intersectionality-based cardiovascular research } \\
\text { questions }\end{array}$ & Intersections of identities explored & Outcome measures \\
\hline 1 & $\begin{array}{l}\text { How effective is aspirin in preventing myocardial infarction in } \\
\text { Black lesbian women? }\end{array}$ & Ethnicity, gender, sex & $\begin{array}{l}\text { Effectiveness of treatment modality } \\
\text { (aspirin) }\end{array}$ \\
\hline 2 & $\begin{array}{l}\text { How accessible, relevant, and effective are heart failure disease } \\
\text { management programs for elderly rural women in Canada? }\end{array}$ & Rurality, age, place of residence & $\begin{array}{l}\text { Accessibility, relevance, and } \\
\text { effectiveness of heart failure disease } \\
\text { management programs }\end{array}$ \\
\hline 3 & $\begin{array}{l}\text { What are the risk factors associated with coronary artery disease } \\
\text { among Black transgender men in urban settings? }\end{array}$ & $\begin{array}{l}\text { Race/ethnicity, gender, place of } \\
\text { residence }\end{array}$ & Risk factors of coronary artery disease \\
\hline 4 & $\begin{array}{l}\text { What are the clinical outcomes after angioplasty among middle- } \\
\text { class Caucasian urban-dwelling women? }\end{array}$ & $\begin{array}{l}\text { Social class, race, place of residence, } \\
\text { gender }\end{array}$ & Clinical outcomes after angioplasty \\
\hline 5 & $\begin{array}{l}\text { What is the compliance with statin prescriptions among retired } \\
\text { older men with cardiovascular disease who do not have } \\
\text { employer-provided insurance coverage? }\end{array}$ & $\begin{array}{l}\text { Employment status, age, gender, } \\
\text { insurance coverage }\end{array}$ & $\begin{array}{l}\text { Compliance with treatment modality } \\
\text { (statins) }\end{array}$ \\
\hline 6 & $\begin{array}{l}\text { What is the prevalence of ST-elevation myocardial infarction } \\
\text { among labor-class Latino men? }\end{array}$ & Social class, race, gender & $\begin{array}{l}\text { Prevalence of ST-elevation myocardial } \\
\text { infarction }\end{array}$ \\
\hline 7 & $\begin{array}{l}\text { How frequently are immigrant women of South Asian descent } \\
\text { referred to a cardiac rehabilitation program? }\end{array}$ & Ethnicity, sex, immigration status & Access to cardiac rehabilitation services \\
\hline 8 & $\begin{array}{l}\text { What are the lived experiences of interactions with cardiologists in } \\
\text { bisexual Hispanic men? }\end{array}$ & Sexual orientation, ethnicity, gender & $\begin{array}{l}\text { Lived experiences of interactions with } \\
\text { cardiologists }\end{array}$ \\
\hline
\end{tabular}




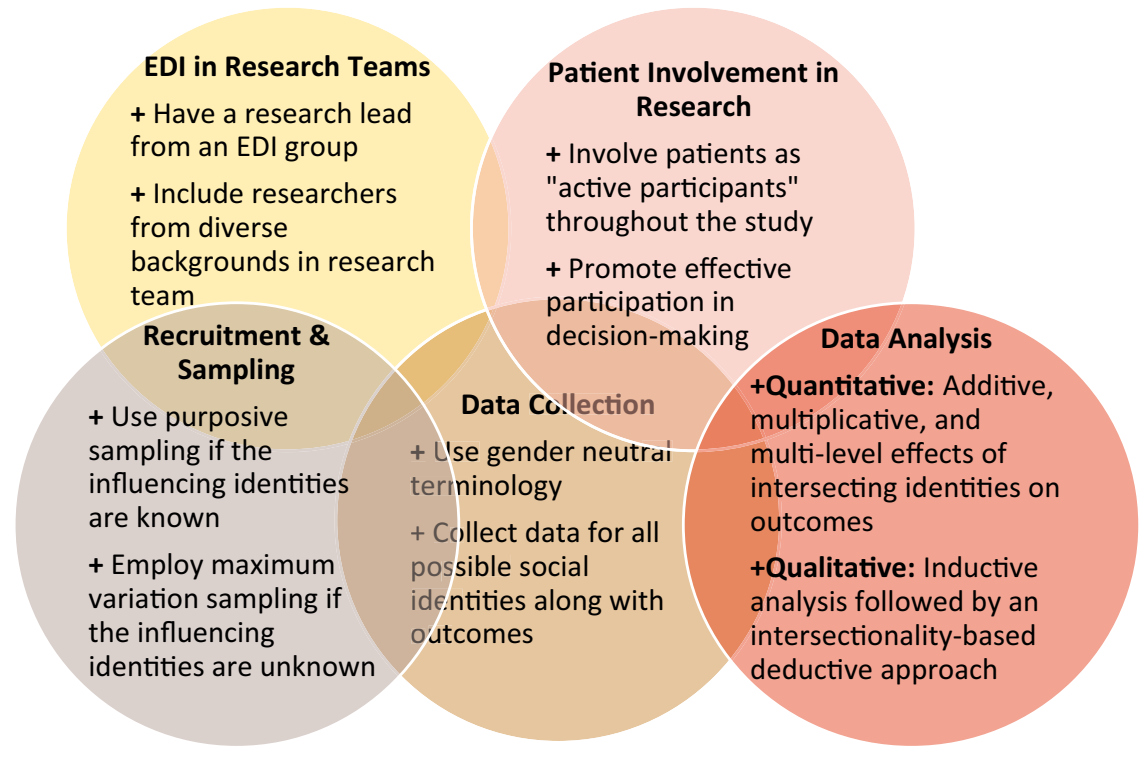

Figure 1. Steps for integrating intersectionality into cardiovascular health research. EDI, Equity, Diversity, and Inclusion.

examined (see Table 1 for some examples of intersectionalitybased cardiovascular health research questions).

Research priorities are often significantly affected by funding agencies' mandates and government-based incentives. ${ }^{22}$ This effect holds true for intersectionality-based research in CVD as well, with the impact that the potential for intersectional research in cardiology is greater when funding agencies call for including diverse patients and research team members, and when there are dedicated incentives for researchers who are promoting intersectionalitybased research. $^{23}$

\section{Equity, Diversity, and Inclusion Representation in the Composition and Leadership of Research Teams}

Increasing the diversity of a research team is one way to promote intersectional research in cardiovascular health and disease. ${ }^{23}$ Having a lead researcher who is from an Equity, Diversity, and Inclusion group, as well as having research team members from diverse backgrounds, promotes rigorous research in the area of health disparities, as each team member brings to the work a unique and personalized understanding of health inequities.

\section{Patient and Public Involvement in Research}

Intersectionality-based research can benefit greatly from patient and public involvement. ${ }^{24}$ Patient engagement, especially of those with relevant intersecting identities, right from the beginning stage of research question formulation and research planning, is essential to ensure that we address the research questions that are relevant to these patients and their communities. ${ }^{24}$

Cardiovascular health research needs patient-partnered interventions, involving patients as active participants so that intersecting identities can be explored through promotion of participation in decision-making, including input into choices and preferences about their care, and opportunities to explore and understand the impacts of various intersecting identities on outcomes. ${ }^{24}$ Only through targeted interventions that proactively involve participants and aim to increase awareness of intersectionality and its impacts can we start to deliver appropriate, acceptable, and equitable care to all.

\section{Recruitment and Sampling}

Recruitment and sampling are significant steps in research, and in which intersectionality can be applied. If the intersecting identities influencing the outcome(s) of interest are already known, a purposive sampling strategy could be employed to include participants with the relevant intersecting identities. ${ }^{25}$ If the exploration is being done for the first time in a particular area and the researcher is completely unaware of the possible intersecting identities that might be relevant, then a maximum variation sample works the best-that is, recruiting a wide range of patients with various intersecting factors. ${ }^{26}$ Moreover, participant-driven snowball sampling is a great resource for intersectionality-based research and is particularly useful for recruiting participants with stigmatized identities that they do not reveal widely, as a means to try to prevent discrimination. ${ }^{25}$

\section{Data Collection}

Data collection is that phase of cardiovascular health research that requires careful consideration of the participants' intersecting identities, and being respectful of the same. Such an approach includes consideration of gender-neutral terminology, providing all possible options for gender identity (man, woman, lesbian, gay, bisexual, transgender, queer, twospirited), ensuring that the participants have the option to indicate all of their social identities as part of the sociodemographic data (age, sex, gender, social class, race, 
ethnicity, immigration status, place of residence-rural/urban), asking them via open- or close-ended questions how their social identities affect the outcome or phenomenon of interest.

\section{Data Analysis}

Intersectionality can be thoroughly applied while analyzing research data, in the case of either quantitative or qualitative analysis. There are intersectionality-based quantitative analytical tools available, such as multiple main effects, statistical interactions, and multilevel modelling, that explore the additive, multiplicative, and multilevel effects of intersecting identities on cardiovascular outcomes, respectively. ${ }^{27}$ Else-Quest and Hyde provide an excellent account of how these analyses can be applied to intersectionalitybased quantitative research. ${ }^{27}$ For intersectionality-informed qualitative analysis, certain frameworks have been proposed. For example, Bowleg proposed open, axial, and selective coding to reflect participants' intersectional experiences. ${ }^{28}$ Similarly, Bilge has proposed performing an inductive thematic analysis followed by applying an intersectionality-informed deductive approach. ${ }^{29}$ Important to note is that whatever the targeted methods, we need to ensure that these are far-reaching and sustainable.

\section{Conclusions}

Given the increasing diversity of the Canadian cardiovascular patient population, we need to investigate the influence of intersectionality on cardiovascular health outcomes, and explore it via research. Intersectionality-driven cardiovascular research has the potential to revolutionize cardiovascular clinical practice, and improve outcomes.

\section{Funding Sources}

The authors have no funding sources to declare.

\section{Disclosures}

The authors have no conflicts of interest to disclose.

\section{References}

1. Ski CF, KIng-Shier KM, Thompson DR. Gender, socioeconomic and ethnic/racial disparities in cardiovascular disease: a time for change. Int J Cardiol 2014;170:255-7.

2. Ski CF, Thompson DR, Fitzsimons D, King-Shier K. Why is ethnicity important in cardiovascular care? Eur J Cardiovasc Nurs 2018;17:294-6.

3. Helmer A, Slater N, Smithgall S. A review of ACE inhibitors and ARBs in Black patients with hypertension. Ann Pharmacother 2018;52:1143-51.

4. Fernandez A, Rodriguez RA. Undocumented immigrants and access to health care. JAMA Intern Med 2017;177:536-7.

5. DeBoer MD, Gurka MJ, Golden SH, et al. Independent associations between metabolic syndrome severity \& future coronary heart disease by sex \& race. J Am Coll Cardiol 2017;69:1204-5.
6. Caceres BA, Streed CG, Corliss HL, et al. Assessing and addressing cardiovascular health in LGBTQ adults. Circulation 2020;142:e321-32.

7. Al-Faham H, Davis AM, Ernst R. Intersectionality: from theory to practice. Annu Rev Law Soc Sci 2019;15:247-65.

8. Hankivsky $\mathrm{O}$, Cormier R, Merich DD. Intersectionality: moving women's health research and policy forward. Women's Health Research Network. Available at: https://bccewh.bc.ca/wp-content/uploads/2012/ 05/2009_IntersectionaliyMovingwomenshealthresearchandpolicyforward. pdf. Accessed June 12, 2021.

9. Yusuf S, Hawken S, Ounpuu S, et al. Effect of potentially modifiable risk factors associated with myocardial infarction in 52 countries (the INTERHEART study): case-control study. Lancet 2004;364:937-52.

10. Gregory PC, LaVeist TA, Simpson C. Racial disparities in access to cardiac rehabilitation. Am J Phys Med Rehabil 2006;85:705-10.

11. Biddle MJ, Moser DK, Pelter MM, Robinson S, Dracup K. Predictors of adherence to self-care in rural patients with heart failure. J Rural Health 2020;36:120-9.

12. Bainey KR, Gupta M, Ali I, et al. The burden of atherosclerotic cardiovascular disease in South Asians residing in Canada: a reflection from the South Asian Heart Alliance. Can J Cardiol Open 2019;1:271-81.

13. Caceres BA, Veldhuis CB, Hughes TL. Racial/Ethnic differences in cardiometabolic risk in a community sample of sexual minority women. Health Equity 2019;3:350-9.

14. Caceres BA, Ancheta AJ, Dorsen C, et al. A population-based study of the intersection of sexual identity and race/ethnicity on physiological risk factors for CVD among U.S. adults (ages 18-59). Ethn Health 2020: $1-22$.

15. Freydberg N, Strain L, Tsuyuki RT, McAlister FA, Clark AM. "If he gives in, he will be gone...": the influence of work and place on experiences, reactions and self-care of heart failure in rural Canada. Soc Sci Med 2010;70:1077-83.

16. Lee KS, Moser DK, Pelter MM, Nesbitt T, Dracup K. Self-care in rural residents with heart failure: what we are missing. Eur J Cardiovasc Nurs 2017;16:326-33.

17. Canada Government. Immigration and Ethnocultural Diversity in Canada. 2018. Available at: https://www.statcan.gc.ca/en/subjects-start/ immigration_and_ethnocultural_diversity. Accessed June 1, 2021.

18. Canada Government. 2020 Annual Report to Parliament on Immigration. In: Immigration, RaCC, ed. Available at: https://www.canada. ca/en/immigration-refugees-citizenship/corporate/publications-manuals/ annual-report-parliament-immigration-2020.html. Accessed June 1, 2021.

19. Canada Government. Socioeconomic profile of the lesbian, gay, and bisexual population, 2015 to 2018. Canada, 2021. Available at: https:// www150.statcan.gc.ca/n1/daily-quotidien/210326/dq210326a-eng.htm. Accessed June 1, 2021.

20. Bank W. Rural Population. Canada, 2021. Available at: https:// www.statcan.gc.ca/en/subjects-start/society_and_community/rural_canada. Accessed June 1, 2021.

21. Kelly-Scott K, Smith K. Aboriginal Peoples: Fact Sheet for Canada. In: Industry Mo, ed. Government of Canada, 2015. Available at: https:// www150.statcan.gc.ca/n1/pub/89-656-x/89-656-x2015001-eng.htm. Accessed June 1, 2021. 
22. Whitley R, Glaser J, Laudel G. The impact of changing funding and authority relationships on scientific innovations. Minerva 2018;56: 109-34.

23. Ortega RF, Yancy CW, Mehran R, Batchelor W. Overcoming lack of diversity in cardiovascular clinical trials: a new challenge and strategies for success. Circulation 2019;140:1690-2.

24. Roche P, Shimmin C, Hickes S, et al. Valuing all voices: refining a trauma-informed, intersectional and critical reflexive framework for patient engagement in health research using a qualitative descriptive approach. Res Involve Engagem 2020;6:1-13.

25. Abrams JA, Tabaac A, Jung S, Else-Quest NM. Considerations for employing intersectionality in qualitative health research. Soc Sci Med 2020;258:113138.
26. Grace D. Intersectionality-informed Mixed Method Research: A Primer. Health Sociol Rev 2014;19:478-90.

27. Else-Quest NM, Hyde J. Intersectionality in quantitative psychological research: II. methods and techniques. Psychol Women Quar 2016;40: 319-36.

28. Bowleg L. When Black + lesbian + woman $\neq$ Black lesbian woman: the methodological challenges of qualitative and quantitative intersectionality research. Sex Roles J Res 2008;59:312-25.

29. Bilge S. Smuggling intersectionality into the study of masculinity: some methodological challenges. Paper presented at: Feminist Research Methods: An International Conference. February 4-9, 2009; Stockholm, Sweden. 